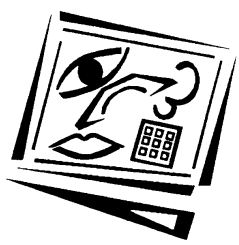

\title{
Pre-service teachers' attitudes towards computer use: A Singapore survey
}

\author{
Timothy Teo \\ Nanyang Technological University
}

\begin{abstract}
The aim of this study is to examine the attitudes towards use of computers among preservice teachers. A sample of 139 pre-service teachers was assessed for their computer attitudes using a Likert type questionnaire with four factors: affect (liking), perceived usefulness, perceived control, and behavioural intention to use the computer. The results of this study showed no gender or age differences among pre-service teachers on computer attitudes. However, there were significant differences for computer attitudes by the subject areas that pre-service teachers had been trained during their university education: Humanities, Sciences, Languages and General (Primary). Correlation analyses revealed significant associations between years of computer use and level of confidence, and computer attitudes. Implications for teacher training and suggestions for further research are provided.
\end{abstract}

\section{Introduction}

Computers are increasingly widespread, influencing many aspects of our social and work lives, as well as many of our leisure activities. As more tasks involve humancomputer interaction, computer skills and knowledge have become more positively correlated with both occupational and personal success. Therefore, as we move into a technology based society, it is important that children's classroom experiences with technology be equitable and unbiased for males and females. In most cases, the teacher is key to effective implementation of the use of computers in the educational system and given that teachers have tremendous potential to transmit beliefs and values to students, it is important to understand the biases and stereotypes that teachers may hold about the use of computers and the factors that act as facilitators to teachers' positive computer usage.

In support of the importance of teachers' attitude towards computer use, Zhao, Tan and Mishra (2001) provided evidence to suggest that the attitudes of teachers are directly related to computer use in the classroom. For example, teachers often view the computer as a tool to accomplish housekeeping tasks, manage their students more efficiently, and to communicate with parents more easily. The success of student learning with computer technology will depend largely on the attitudes of teachers, and their willingness to embrace the technology (Teo, 2006). Gaining an appreciation of the teachers' attitudes towards computer use may provide useful insights into technology integration and acceptance and usage of technology in teaching and learning. 


\section{Teacher's attitudes towards computers}

The success of any initiatives to implement technology in an educational program depends strongly upon the support and attitudes of teachers involved. It has been suggested that if teachers believed or perceived proposed computer programs as fulfilling neither their own or their students' needs, they are not likely to attempt to introduce technology into their teaching and learning. Among the factors that affect the successful use of computers in the classroom are teachers' attitudes towards computers (Huang \& Liaw, 2005). Attitude, in turn, constitutes various dimensions. Some examples of these are perceived usefulness, computer confidence (Rovai \& Childress, 2002), training (Tsitouridou \& Vryzas, 2003), gender (Sadik, 2006), knowledge about computers (Yuen, Law \& Chan, 1999), anxiety, confidence, and liking (Yildirim, 2000).

In many developed countries, nearly all schools are equipped with the infrastructure to conduct ICT mediated teaching and learning. Positive teacher attitudes towards computing are critical if computers are to be effectively integrated into the school curriculum. A major reason for studying teachers' attitude towards computer use is that it is a major predictor for future computer use in the classroom (Myers \& Halpin, 2002). Khine (2001) studied 184 pre-service teachers and found a significant relationship between computer attitude and its use in the institution. This finding was corroborated by Yuen and Ma (2001) who, using the Chinese Computer Attitude Scale for Teachers (CAST), found that 216 secondary teachers in Hong Kong had reported the instructional use of computers and their results revealed that affective attitudes, general usefulness, behavioural control, and pedagogical use to be significant in determining the use of ICT. Kumar and Kumar (2003) reported that most teachers believe that the amount of computer experience has a positive effect on attitude towards computers. Jackson, Ervin, Gardner and Schmitt (2001) indicated that female users, compared with males, are more inclined to hold negative reactions to computers and such differences may have resulted in the different ways of using computers.

In achieving excellence in schools, it is important to ensure that teachers are able to integrate technology into the curriculum. As such, the groundwork must be laid at the trainee or pre-service teacher's level. To do otherwise is to produce future teachers with underdeveloped skills in the use of technology. In the course of their training, pre-service teachers should be provided with the tools and experiences that will be useful for the regular activities in their future job: classroom instruction, research, and problem solving. Using technology enables pre-service teachers to arrange their environment and adjust their instructional strategies (Zhang \& Espinosa, 1997). On the part of teacher educators, there is a need to understand the dimensions that influence pre-service teachers' attitudes towards computers as a means for effective development of teacher training curriculum that will prepare teachers to face the challenges in the information age (Fisher, 2000).

The aim of this study is to examine the profile of a sample of pre-service teachers in Singapore. Specifically, the following questions will be answered:

1. What is the overall profile of pre-service teachers' attitudes towards computer use?

2. Do computer attitudes differ by age, gender, subject domain, years of computer use, and perceived confidence? 


\section{Method}

\section{Sample}

The participants in this research were 139 pre-service teachers enrolled in two programs of study at the National Institute of Education, Nanyang Technological University, Singapore. Of these, 102 were enrolled in the one year Postgraduate Diploma in Education (Secondary) and 37 were enrolled in the one year Postgraduate Diploma in Education (Primary). Among the 102 participants enrolled in the Secondary program, 48 were graduates in sciences (mathematics, physics), 29 were graduates in languages (English language, English literature), and 25 were graduates in humanities (history). All participants were volunteers and no course credits were given for their participation. There were 84 females (60.4\%) participants and the mean age of all participants was 24.2 years $(\mathrm{SD}=3.74)$. The average number of years of computer use was 9.63 years $(\mathrm{SD}=3.27)$. The sample was homogeneous-participants were primarily Chinese Singaporeans, and all were English speaking. Moreover, all had similar educational experiences; all participants had a bachelor's degree (a prerequisite for joining these programs). All participants reported ready access to computers at home and at the Institute.

\section{Procedure}

Data was collected from the participants on a voluntary basis during the first semester of the 2007 academic year. At all occasions, the author was present throughout the data collection process. After a brief introduction to the research, the survey questionnaires were distributed to students. On the average, students took about 15 minutes to complete the survey forms. There were also no queries from the participants. Participants were told that they could withdraw their participation during or after the data collection.

\section{Instrument}

The instrument included sections on participants' demographic background, computer experience and perceived confidence, and the Computer Attitude Scale (CAS), developed by Selwyn (1997). Computer experience in this study was measured by asking the participants "On average, how many years have you used the computer?" Perceived confidence was measured by asking the participants, "How confident are you in using the computer?", with responses on a five-point scale from $1=$ not confident at all to $5=$ very confident.

The CAS was used to measure the pre-service teachers' attitudes towards computer use. It is a 21-item questionnaire that consists of four components of computer attitudes (Table 1). The first component, 'Affect', is composed of six items and measures feelings towards computers. 'Perceived Usefulness' is composed of five items that measure the individual's beliefs about the usefulness of computers in their job. 'Perceived Control', is composed of six items that measure the perceived comfort level or difficulty of using computers. The fourth component, 'Behavioural Intention', is composed of four items that measure behavioural intentions and actions with respect to computers.

Participants responded to the CAS using a five-point scale of strongly disagree (1), disagree (2), neutral (3), agree (4), and strongly agree (5). The scores from the items on 
each component were aggregated to provide individual scores on each component. In this study, the negative items were reversed coded in order that meaningful analyses at the sub-scale level could be conducted. The CAS has been found to be a reliable instrument to measure attitude towards computer among teacher education students. Using the CAS on 131 undergraduate students in early childhood education, Sexton, King, Aldridge and Goodstadt-Killoran (1999) reported that the CAS possessed high reliability (alpha $=0.90)$.

Table 1: Items in the Computer Attitude Scale

\begin{tabular}{|c|c|c|}
\hline \multirow{6}{*}{$\begin{array}{l}\text { Affective } \\
\text { component } \\
\text { (six items) }\end{array}$} & AFF1 & $\begin{array}{l}\text { If given the opportunity to use a computer, I am afraid that I might damage } \\
\text { it in some way* }\end{array}$ \\
\hline & AFF2 & I hesitate to use a computer for fear of making mistakes I can't correct ${ }^{*}$ \\
\hline & AFF3 & I don't feel apprehensive about using a computer \\
\hline & AFF4 & Computers make me feel uncomfortable* \\
\hline & AFF5 & Using a computer does not scare me at all \\
\hline & AFF6 & I hesitate to use a computer in case I look stupid* \\
\hline \multirow{5}{*}{$\begin{array}{l}\text { Perceived } \\
\text { usefulness } \\
\text { component } \\
\text { (five items) }\end{array}$} & PU1 & Computers help me improve my work better \\
\hline & PU2 & Computers make it possible to work more productively \\
\hline & PU3 & Computers can allow me to do more interesting and imaginative work \\
\hline & PU4 & Most things that a computer can be used for I can do just as well myself ${ }^{*}$ \\
\hline & PU5 & $\begin{array}{l}\text { Computers can enhance the presentation of my work to a degree which } \\
\text { justifies the extra effort }\end{array}$ \\
\hline \multirow{6}{*}{$\begin{array}{l}\text { Perceived } \\
\text { control } \\
\text { component } \\
\text { (six items) }\end{array}$} & PC1 & $\begin{array}{l}\text { I could probably teach myself most of the things I need to know about } \\
\text { computers }\end{array}$ \\
\hline & PC2 & I can make the computer do what I want it to \\
\hline & PC3 & $\begin{array}{l}\text { If I get problems using the computer, I can usually solve them one way or } \\
\text { the other }\end{array}$ \\
\hline & PC4 & I am not in complete control when I use a computer* \\
\hline & PC5 & I need an experienced person nearby when I use a computer \\
\hline & PC6 & I do not need someone to tell me the best way to use a computer \\
\hline \multirow{4}{*}{$\begin{array}{l}\text { Behavioural } \\
\text { intention } \\
\text { component } \\
\text { (four items) }\end{array}$} & BI1 & I would avoid taking a job if I knew it involved working with computers* \\
\hline & BI2 & I avoid coming into contact with computers in school ${ }^{*}$ \\
\hline & BI3 & I only use computers at school when 1 am told to ${ }^{*}$ \\
\hline & BI4 & I will use computers regularly throughout school. \\
\hline
\end{tabular}

\section{Results}

\section{Overall profile of the computer attitudes among pre-service teachers}

Attitude towards computer use was measured in terms of the affective, perceived usefulness, perceived control, and behavioural intention components in the CAS (Selwyn, 1997). All 139 participants responded to all items in the CAS and no missing data was found in the survey. Table 2 presents the participants' mean scores with the standard deviations of the four subscales. The participants scored the lowest on the perceived control $($ mean $=3.54)$ followed by the perceived usefulness subscale $($ mean $=3.98)$. The mean scores for the affective and behavioural intention subscales are the same (mean = 4.00). The means suggest that participants were more positive about their affect towards computers and intention to use computer than their perceptions of the usefulness of the computer and their control of the computer. The results, however, also suggested that participants perceived themselves to be in control of computer to a lesser degree than they thought the computer was useful and had liked (affective) and 
intent to use (behavioural) the computer. At the global level, the overall computer attitude is well above the mid-point of the scale (3.00) and this indicated that participants held a positive attitude towards the computer. The reliability coefficient for each subscale ranges from moderate (.53) to high (.79). The reliability for the whole scale is high (.86).

Table 2: Descriptive statistics and reliability coefficient for each subscale $(\mathrm{n}=139)$

\begin{tabular}{|l|c|c|c|c|}
\hline \multicolumn{1}{|c|}{ Subscale } & No of items & Mean & SD & alpha \\
\hline Affective & 6 & 4.00 & .77 & .79 \\
\hline Perceived usefulness & 5 & 3.98 & .51 & .66 \\
\hline Perceived control & 6 & 3.54 & .54 & .61 \\
\hline Behavioural intention & 4 & 4.00 & .83 & .76 \\
\hline Overall computer attitudes & 21 & 3.85 & .52 & .86 \\
\hline
\end{tabular}

The relationship among the subscales is shown in Table 3. All subscales correlate significantly at the $\mathrm{p}<.01$ level and the coefficients range from .23 to .61 . This suggests that the four components were fairly independent to be used as independent variables. This allows us to examine the computer attitudes of pre-service teachers by each subscale.

Table 3: Correlation matrix of the subscales*

\begin{tabular}{|l|c|c|c|}
\hline \multicolumn{1}{|c|}{ Subscale } & Affective & PU & PC \\
\hline Perceived usefulness (PU) & .23 & & \\
\hline Perceived control (PC) & .61 & .31 & .53 \\
\hline Behavioural intention (BI) & .53 & .28 & \\
\hline
\end{tabular}

${ }^{*} \mathrm{p}<.01$ (2-tailed)

A confirmatory factor analysis (CFA) was conducted to test the validity of the factor structure of the CAS. Analysis performed using AMOS 7.0 (Arbuckle, 2006) using maximum likelihood (ML) as the estimation procedure. In terms of the sample size required to use the ML estimator appropriately, Ding, Velicer and Harlow (1995) recommended that the minimum sample size to use MLE appropriately should be between 100 to 150 participants. Following the recommendations of Boomsma (2000) and McDonald \& Ho (2002), several fit criteria were applied.

In addition to the chi-square test, other test indices were used. These included the root mean square error of approximation (RMSEA), which is a measure of the discrepancy per degree of freedom between the model and the covariance-matrix in the population, the standardised root mean square residual (SRMR), which is the average difference between observed and reproduced correlations, the non-normed fit index (NNFI), indicating the proportional improvement of the fit of the model relative to the independence model, and the Comparative Fit Index (CFI), which assesses the relative improvement in fit of the researcher's model compared with the baseline model.

The model fit was considered acceptable when both SRMR $<0.08$ and RMSEA $<0.06$ (Hu \& Bentler, 1999). Both the NNFI and CFI should be at least .90. Results of the CFA indicated a good model fit (chi-squared $=199.325, \mathrm{df}=179, \mathrm{p}<.142 ; \mathrm{NNFI}=.84 ; \mathrm{CFI}=$ .98 ; RMSEA $=.03$; SRMR $=.06$ ). Table 4 shows the regression estimates and the $t$ values of the items and their respective scales. 
Table 4: Regression estimate of the first order CFA of the Computer Attitude Scale

\begin{tabular}{|c|c|c|c|c|c|}
\hline & & Estimate & $\begin{array}{l}\text { Standard } \\
\text { error }\end{array}$ & $t$ value & $p$ \\
\hline \multirow[t]{6}{*}{ Affect } & AFF1 & $1.000^{* *}$ & -- & -- & -- \\
\hline & AFF2 & 1.030 & .086 & 12.024 & * \\
\hline & AFF3 & 1.067 & .079 & 13.509 & * \\
\hline & AFF4 & .985 & .084 & 11.700 & * \\
\hline & AFF5 & .885 & .082 & 10.751 & * \\
\hline & AFF6 & .985 & .079 & 12.421 & * \\
\hline \multirow{5}{*}{$\begin{array}{l}\text { Perceived } \\
\text { usefulness }\end{array}$} & PU1 & $1.000^{* *}$ & -- & -- & -- \\
\hline & PU2 & 1.081 & .238 & 4.545 & * \\
\hline & PU3 & .355 & .188 & 1.889 & .05 \\
\hline & PU4 & 1.449 & .312 & 4.643 & * \\
\hline & PU5 & 1.084 & .260 & 4.167 & * \\
\hline \multirow{6}{*}{$\begin{array}{l}\text { Perceived } \\
\text { control }\end{array}$} & PC1 & $1.000^{* \star}$ & -- & -- & -- \\
\hline & PC2 & 1.314 & .322 & 4.080 & * \\
\hline & PC3 & .900 & .216 & 4.166 & * \\
\hline & PC4 & 1.856 & .405 & 4.578 & * \\
\hline & PC5 & 1.312 & .307 & 4.271 & * \\
\hline & PC6 & .867 & .260 & 3.332 & * \\
\hline \multirow{4}{*}{$\begin{array}{l}\text { Behavioural } \\
\text { intention }\end{array}$} & BI1 & $1.000^{\star *}$ & -- & -- & -- \\
\hline & BI2 & .630 & .257 & 2.457 & .014 \\
\hline & BI3 & 1.324 & .431 & 3.070 & .002 \\
\hline & BI4 & 1.245 & .371 & 3.351 & * \\
\hline
\end{tabular}

\section{Computer attitudes and age, gender, subject domain, years of computer use, and perceived confidence}

\section{MANOVA analyses}

Preliminary assumption testing was conducted to check for multivariate normality and equality of variance. No violations were found multivariate normality. For the equality of variance, there was a violation for the dependent variable behavioural. Pallant (2005) suggested that if this assumption was violated, a more conservative alpha level for determining the significance for that variable be set. For this study, an alpha value of $p$ $<.01$ will be used.

A one way, between groups multivariate analysis of variance was performed on the four dependent variables (affective, perceived usefulness, perceived control, behavioural intention) for age and gender. No significant differences were found: $F(4$, $134)=1.788, p<.135$; Wilks' lambda $=0.949$, partial eta-squared $=0.051$. There was also no significant difference for gender and the four dependent variable: $F(4,134)=2.156, p$ $<.077$; Wilks' lambda $=0.940$, partial eta-squared $=0.060$. These results suggest that both male and females pre-service teachers at all ages were similar in their attitudes towards the computer.

A one way, between groups multivariate analysis of variance was performed on the four dependent variables (affective, perceived usefulness, perceived control, behavioural intention) for subject domain (Humanities, Sciences, Languages, and General (Primary)). There was a significant difference by subject domain on the combined dependent variable computer attitude: $F(12,126)=7.849, p<.001$, Wilks' 
lambda $=0.532$, partial eta-squared $=0.190$. The four groups (subject domain) differ in their perceptions of how much they like computers (affective): $F(3,135)=18.087, p<$ .001; how much control they have over computers (perceived control): $F(3,135)=9.603, p$ $<.001$; and their behavioural intentions in using computers (behavioural intention): $F(3$, $135)=29.530, p<.001$. For the affect, perceived usefulness and behavioural intention components, there were significant differences between the students in the General (Primary) program and those in the other programs. For the perceived control component, significant differences were found for students in all except those in the language program. The results suggest that while most pre-service teachers were similar in their attitudes towards the computer, they had different views regarding each component within computer attitude. In general, students in the subject specific classes were similar in their computer attitudes compared to those in the General (Primary) classes.

\section{Correlation analyses}

The mean years of computer use was 9.63 years $(S D=3.27)$ and that of computer confidence was $3.73(\mathrm{SD}=.89)$. Between the 'Year of computer use' and level of computer confidence, there was a significant correlation $(\mathrm{r}=.23, \mathrm{n}=139, p>.01)$. To examine the relationship between computer attitudes and years of computer use and level of computer confidence among pre-service teachers, a bivariate correlation was performed. Table 5 shows the summary.

Table 5: Summary of correlations by years of computer use and computer confidence

\begin{tabular}{|l|c|c|}
\hline \multicolumn{1}{|c|}{ Subscale } & Computer use & Computer confidence \\
\hline Affective & $.209^{*}$ & $.314^{* *}$ \\
\hline Perceived usefulness & -.082 & $.248^{* *}$ \\
\hline Perceived control & $.195^{*}$ & $.507^{* *}$ \\
\hline Behavioural intention & $.200^{*}$ & .159 \\
\hline Computer attitudes & $.188^{*}$ & $.391^{* *}$ \\
\hline${ }^{*} p<.05{ }^{* *} p<.01$ & &
\end{tabular}

The results show a non-significant but inverse correlation between the years of computer use and perceived usefulness. There was also no significant relationship between the level of computer confidence and behavioural intention to use computers. However, there were significant correlations between the overall computer attitudes and years of computer use and level of computer confidence.

\section{Discussion}

Overall, the participants showed positive attitudes towards the computer, as shown by the mean score for each subscale being 3.5 and above (on a 5-point scale). The overall positive level of computer attitudes could be attributed to the availability and accessibility to computers given to the pre-service teachers at various stages of their education. This had taken place prior to the participants enrolling in the teacher training program. In 1997, an initiative implemented by Singapore's Ministry of Education called the MasterPlan for IT in Education (Masterplan) ensured that all students would be given access to an IT-enriched environment in schools, starting at the primary level (MOE, 1997). Apart from increasing the use of computers in schools, this initiative has also contributed towards increasing home computer ownership among the students, which could have promoted greater opportunities with 
computers and related technologies, especially the Internet. Chronologically, the participants of this study would have benefited from the goals of the MasterPlan in ways that may have shaped their computer attitudes in a positive direction.

This study found no significant relationship for age and gender, and computer attitudes. This finding does not support past research which suggested significant differences in computer attitudes by gender (e.g. Margolis \& Fisher, 2002; Markauskaite, 2006). For example, Houtz and Gupta (2001) found that males and female had rated themselves on their ability to use the computer in significantly different ways. Other studies have suggested that the masculine image of the computer has deterred females from benefiting from the technology and this has made them less confident or more anxious (Culley, 1988), resulting in females holding more negative attitudes to computers than males (Campbell, 1990). Consequently, female students tended to use computers less even when given equal access (Muira, 1987). The research on gender and computing has often reported, though not conclusively, that males have more experience and make more use of computers (Brosnan \& Lee, 1998; Balka \& Smith, 2000).

It is usual to consider the issue of gender in the context of other user variables such as self efficacy, computer anxiety, and computer experience. For example, Chua, Chen and Wong (1999) and Coffin and Mackintyre (2000) in their meta-analyses on the relationships between computer anxiety, computer attitudes, computer self efficacy and computer experience stated that most findings usually reinforce the gender effects and suggested that greater levels of computer experience are associated with lower computer experience and more positive computer attitudes. Females usually also have more negative attitudes towards computers (Durndell \& Thompson, 1997) and greater computer anxiety (Mcllroy, Bunting, Tierney \& Gordon, 2001) than males. Research on computer self efficacy in general also revealed that males on average tend to acquire computer self efficacy faster than females (Todman, 2000).

The lack of computer attitude differences between genders in this study is consistent with research that revealed changing attitudes among female computer users. For example, females may have been socialised differently in today's computer generation to be more comfortable with computers and this may have resulted in lessening the barriers perceived by females, in the lack of training opportunities for them (Ray, Sormunen \& Harris, 1999). To a large part, North and Noyes (2002) felt that increased use of computers for teaching and learning in schools has worked against the development of gender differences as reported in previous research, a situation consistent with the use of computers in the Singapore schools (Teo, 2006).

The findings in this study showed that years of computer use and level of computer confidence are positively correlated with positive computer attitudes, supporting previous research (Shashaani, 1997). In part, using computers more frequently and developing a variety of computer related skills and techniques increases one's knowledge of the computer as a whole. This widens one's learning horizon and potential that in turn promotes a positive feeling towards the computer (Houtz \& Gupta, 2001). The results of this study shows that years of computer usage is positively correlated with level of computer confidence. While this may seem obvious, it is important that the length of computer use is associated with the successful use of the computer in order that positive feelings can be fostered (Huang \& Liaw, 2005). Otherwise, a prolonged unsuccessful period of computer use may serve as a barrier 
instead of facilitating further usage of the computer (Lim \& Khine, 2006). This is corroborated by an observation in this study, although not statistically significant, which suggests an inverse relationship between pre-service teachers' length of computer use and perceived usefulness of the computer.

Participants who majored in different subject domains (Humanities, Sciences, Languages, and General (Primary)) differed in their perceptions of how much they like computers (affective), how much control they have over computers (perceived control), and their behavioural intentions (behavioural) in using computers. Differences in computer attitudes among students who majored in different subject domains are consistent with the literature. For example, it was found that students in sciences such as medicine had less positive attitudes towards the use of computers, due to the fact that medical training was conducted mainly by using face to face methods (Khine, 2001). In this study, there were significant differences in attitudes between students in the General (Primary) course and those who were training to teach specific subjects (e.g. science, humanities). Supporting Khine (2001), it was possible that the former could have been shaped by their vocational expectations. Specifically, students who expect to teach in Primary (General) may hold different perceptions of usefulness and control, relative to the students in the subject specific courses, who are more focused on the computer related tools that they would expect to use when they become teachers in the schools.

However, participants from all the subject areas perceived the computers to be useful in their work. It is reasonable to expect that, given the thrust of the use of ICT in the schools for teaching and learning and their exposure to computers during teacher training, coupled with modelling by the lecturers on computer usage, these participants were in a conducive environment that nurtured a development of positive attitudes towards computers.

\section{Conclusion}

Teachers are change agents in schools. They are key drivers who play crucial roles in technology integration in the schools and classrooms. It is important for them to possess positive computer attitudes since attitudes has been found to be linked to usage and intention to use, variables that determine successful technology integration in education. In other words, computer attitudes, whether positive or negative, affect how teachers respond to technology in an instructional setting or learning environment. This in turn affects the way students react to computers in schools (Teo, 2006) and current and future computer usage. Despite the high level of technology in schools, the extent to which it is optimised depends on teachers having a positive attitude towards it (Huang \& Liaw, 2005). This study suggests a need for teacher educators to provide a conducive and non-threatening environment for pre-service teachers to experience success in using the computers, with a view to allowing preservice teachers to gain competence and confidence in using computers for teaching and learning.

There are several limitations in this study. Firstly, the data collected was through self reports and this may lead to a common method variance, a situation that may inflate the true associations between variables, resulting in spurious significant findings. Secondly, the sample size in this study is relatively small, thus limiting the extent to which the findings of this study may be generalised. Thirdly, the data was collected 
using a cross-sectional, single administration design and it was not possible to establish the stability of the attitudes of the participants. Finally, the variables chosen in this study were determoned by the selection of the CAS for data collection. As a result, other significant variables that influence computer attitudes are excluded, leading to a limited understanding of computer attitudes. For example, Teo, Lee and Chai (2008) and Teo (in press) found evidence to suggest that that computer attitudes may be studied using the Technology Acceptance Model (TAM) with variables external to the model, such as subjective norms, facilitating conditions, and technological complexity. Outside the premise of the TAM, Teo (2007) found the perceived importance of computers, enjoyment, and anxiety to be associated significantly with computer attitudes. Future research may include comparison of the results of this study against a larger sample using a longitudinal design to examine computer attitudes over time. Other variables could be added to examine their impact on computer attitudes.

This study provides a glimpse of selected variables that affect the computer attitudes of pre-service teachers. Future studies could include a systematic examination of all aspects of teacher education and how these interact to impact on pre-service teachers' attitudes, acceptance, and usage of the computer as a tool for instructional purposes and professional development.

\section{References}

Arbuckle, J. L. (2006). AMOS 7.0. [Computer software]. Chicago, IL: SPSS.

Balka, E. \& Smith, R. K. (Eds) (2000). Women, work and computerization: Charting a course to the future. Norwell, MA: Kluwer.

Brosnan, M. \& Lee, W. (1998) A cross-cultural comparison of sex differences in computer attitudes and anxieties: The United Kingdom and Hong Kong. Computers in Human Behavior, $14(4), 559-577$.

Boomsma, A. (2000). Reporting on structural equation analyses. Structural Equation Modeling, 7, 461-483.

Campbell, N. J. (1990). High school students' computer attitudes and attributions: Gender and ethnic differences. Journal of Adolescent Research, 5, 485-499.

Chua, S. L., Chen, D.T. \& Wong, A. F. L. (1999). Computer anxiety and its correlates: A metaanalysis. Computers in Human Behavior, 15(5), 609-623.

Coffin, R. \& Mackintyre, P. (2000). Cognitive, motivation and affective processes associated with computer related performance: A path analysis. Computers in Human Behavior, 16(2), 199-222.

Culley, L. (1988). Option choices and careers guidance: Gender and computing in secondary schools. British Journal of Counseling and Guidance, 16, 72-82.

Ding, L., Velicer, W. F. \& Harlow, L. L. (1995). Effects of estimation methods, number indicators per factor, and improper solutions on structural equation modeling fit indices. Structural Equation Modeling, 2, 119-144.

Durndell, A. \& Thomson, K. (1997). Gender and computing: A decade of change? Computers in Education, 28, 1-9.

Fisher, M. (2000). Computer skills of initial teacher education students. Journal of Information Technology for Teacher Education, 9(1), 109-123. http:/ / www.informaworld.com/smpp/43132900180367837 / ftinterface $\sim$ content $=$ a $739084579 \sim$ fulltext $=713240930$ 
Houtz, L. E. \& Gupta, U. G. (2001). Nebraska high school students' computer skills and attitudes. Journal of Research on Computing in Education, 33(3), 316-326.

Hu, L. \& Bentler, P. M. (1999). Cutoff criteria for fit indexes in covariance structure analysis: Conventional criteria versus new alternatives. Structural Equation Modeling, 6(1), 1-55.

Huang, H. M. \& Liaw, S. S. (2005). Exploring user's attitudes and intentions toward the web as a survey tool. Computers in Human Behavior, 21(5), 729-743.

Jackson, L. A., Ervin, K. S., Gardner, P. D. \& Schmitt, N. (2001). Gender and the Internet: Women communicating and men searching. Sex Roles, 44(5), 363-379.

Khine, M. S. (2001). Attitudes toward computers among teacher education students in Brunei Darussalam. International Journal of Instructional Media, 28(2), 147-153.

Kumar, P. \& Kumar, A. (2003). Effect of a web-based project on pre-service and inservice teachers' attitude toward computers and their technology skills. Journal of Computing in Teacher Education, 19(3), 87-91.

Lim, C. P. \& Khine, M. S. (2006). Managing teachers' barriers to ICT integration in Singapore schools. Journal of Technology and Teacher Education, 14(1), 97-125.

Margolis, J. \& Fisher, A. (2002). Unlocking the clubhouse: Women in computing. Cambridge, MA: The MIT Press.

Markauskaite, L. (2006). Gender issues in preservice teachers' training: ICT literacy and online learning. Australasian Journal of Educational Technology, 22(1), 1-20. http: / / www.ascilite.org.au/ajet/ ajet22/markauskaite.html

McDonald, R. P. \& Ho, M. R. (2002). Principles and practice in reporting structural equation analyses. Psychological Methods, 7, 64-82.

Mcllroy, D., Bunting, B., Tierney, K. \& Gordon, M. (2001). The relation of gender and background experience to self-reported computing anxieties and cognitions. Computers in Human Behavior, 17, 21-33.

Myers, J. M. \& Halpin, R. (2002). Teachers' attitudes and use of multimedia technology in the classroom: Constructivist-based professional development training for school districts. Journal of Computing in Teacher Education, 18(4), 133-140.

Ministry of Education (1997). MasterPlan for information technology. Singapore: Ministry of Education.

Muira, L. T. (1987). Gender and socioeconomic status differences in middle-school computer interest and use. Journal of Early Adolescence, 7, 243-254.

North, A.S. \& Noyes, J.M. (2002). Gender influences on children's computer attitudes and cognitions. Computers in Human Behavior, 18(2), 135-150.

Pallant, J. (2005). SPSS survival manual: A step by step guide to data analysis using SPSS. 2nd ed. Allen \& Unwin: Sydney.

Ray, C. M., Sormunen, C. \& Harris, T. M. (1999). Men's and women's attitudes toward computer technology: A comparison. Office Systems Research Journal, 17(1), 1-8.

Rovai, A. P. \& Childress, M. D. (2002). Explaining and predicting resistance to computer anxiety reduction among teacher education students. Journal of Research on Technology in Education, 35(2), 226-235.

Sadik, A. (2006). Factors influencing teachers' attitudes toward personal use and school use of computers: New evidence from a developing nation. Evaluation Review, 30(1), 86-113. 
Selwyn, N. (1997). Students' attitudes toward computers: Validation of a computer attitude scale for 16-19 education. Computers E Education, 28, 35-41.

Sexton, D., King. N., Aldridge, J. \& Goodstadt-Killoran, I. (1999). Measuring and evaluating early childhood prospective practitioners' attitudes toward computers. Family Relations, $48(3), 277-285$.

Shashaani, L. (1997). Gender differences in computer attitudes and use among college students. Journal of Educational Computing Research, 16, 37-51.

Teo, T. (in press). A path analysis of pre-service teachers' attitudes toward computer use: applying and extending the Technology Acceptance Model in an educational context. Interactive Learning Environments.

Teo, T. (2006). Attitudes toward computers: A study of post-secondary students in Singapore. Interactive Learning Environments, 14(1), 17-24.

Teo, T. (2007). Perceived importance, enjoyment, and anxiety as correlates of computer attitudes. Psychological Reports, 100, 127-135.

Teo, T., Lee, C. B. \& Chai, C. S. (2008). Understanding pre-service teachers' computer attitudes: Applying and extending the technology acceptance model. Journal of Computer-Assisted Learning, 24(2), 128-143.

Tsitouridou, M. \& Vryzas, K. (2003). Early childhood teachers' attitudes towards computer and information technology: The case of Greece. Information Technology in Childhood Education Annual, 1, 187-207.

Todman, J. (2000). Gender differences in computer anxiety among university entrants since 1992. Computers \& Education, 34(1), 27-35.

Yildirim, S. (2000). Effects of an educational computing course on pre-service and inservice teachers: A discussion and analysis of attitudes and use. Journal of Research on Computing in Education, 32(4), 479-495.

Yuen, H. K. \& Ma, W. K. (2002). Gender differences in teacher computer acceptance. Journal of Technology and Teacher Education, 10(3), 365-382.

Yuen, H. K., Law, N. \& Chan, H. (1999). Improving IT training for serving teachers through evaluation. In G. Cumming, T. Okamoto \& L. Gomez (Eds), Advanced research in computers and communications in education, Amsterdam: IOS Press, Vol. 2, pp.441-448.

Zhao, Y., Tan, H. S. \& Mishra, P. (2001). Teaching and learning: Whose computer is it? Journal of Adolescent \& Adult Literacy, 44(4), 348-354.

Zhang, Y. \& Espinoza, S. (1997). Affiliations of computer self-efficacy and attitudes with need for learning computer skills. Journal of Educational Computing Research, 17, 371-383.

Timothy Teo

Learning Sciences \& Technologies

National Institute of Education

Nanyang Technological University

1 Nanyang Walk, Singapore 637616

Email: timothy.teo@nie.edu.sg 